\title{
Aggressive Fibroma of the Popliteal Fossa Presenting with Vascular Compression of Popliteal Vessels - A Rare Case Report
}

Aggarwal Roopak MBBS, $\mathrm{MD}^{1}$, Chaudhary Amit MBBS, MS, $\mathrm{MCH}^{2 *}$, Maheshwari Neha MBBS, $\mathrm{DNB}^{3}$, Singh Amit MBBS, MS, $\mathrm{MCH}^{4}$

${ }^{1}$ Associate Professor, Pathology C/O Department of Pathology, Uttar Pradesh University of Medical Sciences, Saifai, Etawah

${ }^{2}$ Assistant Professor, Cardiothoracic and Vascular Surgery C/O Department of Cardiothoracic and Vascular Surgery, Uttar Pradesh University of Medical

${ }^{3}$ Consultant, Radiologist C/O OM diagnostics, Kamla Nagar, Agra

${ }^{4}$ Associate Professor, Cardiothoracic and vascular surgery C/O Department of cardiothoracic and vascular Surgery, Uttar Pradesh University of Medical Sciences, Saifai, Etawah

DOI: $10.36348 /$ sjpm.2020.v05i01.002 $\quad$ | Received: 20.12.2019| Accepted: 27.12.2019| Published: 22.01 .2020

*Corresponding author: Dr. Amit Chaudhary

\section{Abstract}

A 25 year old man presented in 2019 with increasing pain, coldness of left lower limb and lump at left popliteal fossa. Magnetic resonance imaging was performed before surgery and histopathological and immunohistochemical studies were performed after surgery. This demonstrated a $8 \times 6 \times 2 \mathrm{~cm}$ well defined soft tissue mass at the posterior compartment of knee engulfing tendons. A histopathological differential diagnosis of benign spindle cell lesion leiomyoma and benign fibrous tumour was made. We describe this rare case of fibroma at posterior compartment of the knee with immunohistochemistry and treatment.

Keywords: Aggresive fibroma; Popliteal fossa; Resection.

Copyright @ 2020: This is an open-access article distributed under the terms of the Creative Commons Attribution license which permits unrestricted use, distribution, and reproduction in any medium for non-commercial use (NonCommercial, or CC-BY-NC) provided the original author and sources are credited.

\section{INTRODUCTION}

Fibroma is a rare and benign soft tissue tumour that usually originates from tendon or tendon sheaths in fingers, toes, and wrist joints. About $99 \%$ of fibroma arise from the tendon sheaths or tendons, and rarely occur in joint capsules [1-3]. Commonly, patient presents with a painless, minimally tender solitary mass. However, cases associated with triggering or compression neuropathies have been described when underlying tendons or nerves are affected [3-8].

We herein present a case of fibroma of popliteal fossa with Severe Vascular symptoms of left lower limb of short duration.

\section{CASE REPORT}

A 25 year old man presented with a 3 month history of increasing pain, coldness of left lower limb and lump at left popliteal fossa. There was no history of infection and trauma before.

Physical examination demonstrated a mass in popliteal fossa with limited range of motion and pain after walk and on bending knee, decreased pulsations of left anterior, posterior tibial artery dorsalis pedis arteries.

Color Doppler left lower limb was suggestive of external compression by a mass in the left popliteal fossa.

MRI demonstrated a $8 \times 6 \times 2 \mathrm{~cm}$ well defined soft tissue mass at the posterior compartment of knee engulfing tendons. There was no osseous erosion or joint effusion noted. Based on this, the differential diagnosis included giant cell tumour of tendon sheath, lipoma, leiomyoma and neuroma

With these radiological investigations, the patient underwent resection of tumor by CTVS surgeon team as there was clear evidence of decreased Vascularity in the left lower limb below the tumor.The tumour which was grossly firm and white colored was carefully dissected from the flexor tendons and neurovascular structures. Tumor was compressing popliteal vessels though not infiltrating into it grossly. The external surface of the mass was smooth without any gross abnormalities or disruption. Histology reveals irregular bundles of spindle shaped cells with no atypia 
or pleomorphism in a collagenous background [fig 1(a) \& Fig 1(b)]

Diagnosis of benign spindle cell lesion $d / d$ of leiomyoma and benign fibrous tumour was given on histopathology. Immunohistochemistry staining was negative for SMA, Desmin and S-100. Positive for vimentin (fig 2) Final diagnosis of fibroma is made on IHC.

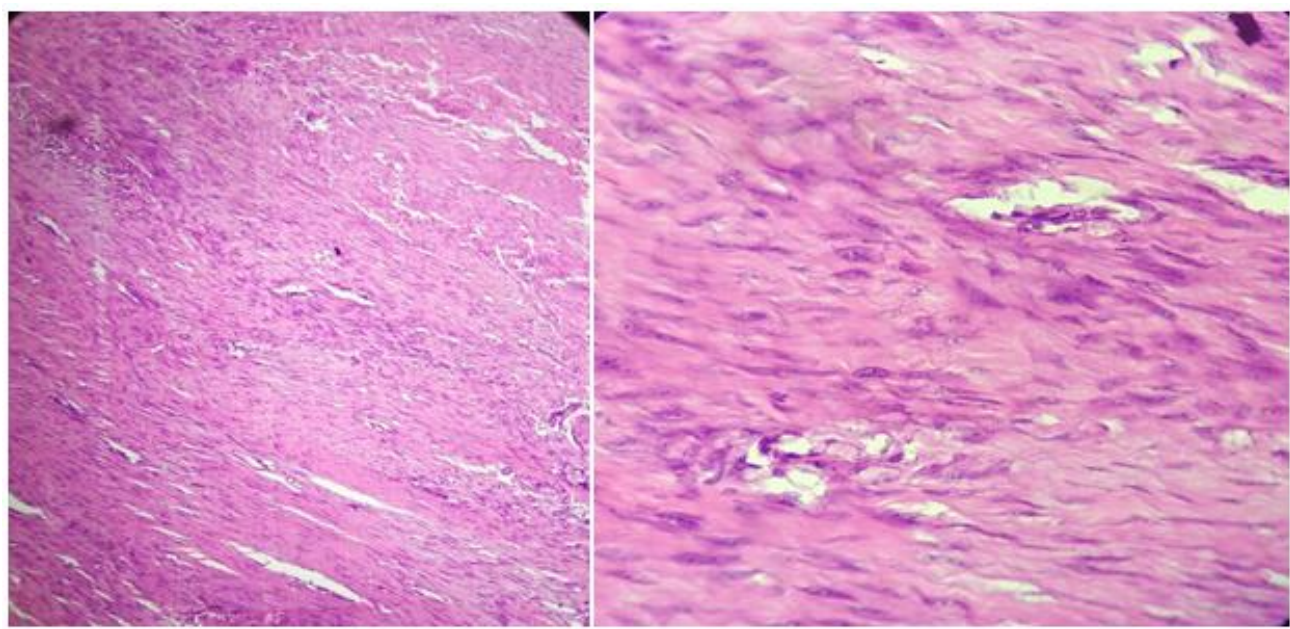

Fig-1a\&b: 1(a)-Bundles of spindle shaped cells with no atypia orpleaomorphism(100X). 1(b) spindle shed cells in collagenous background (400X)

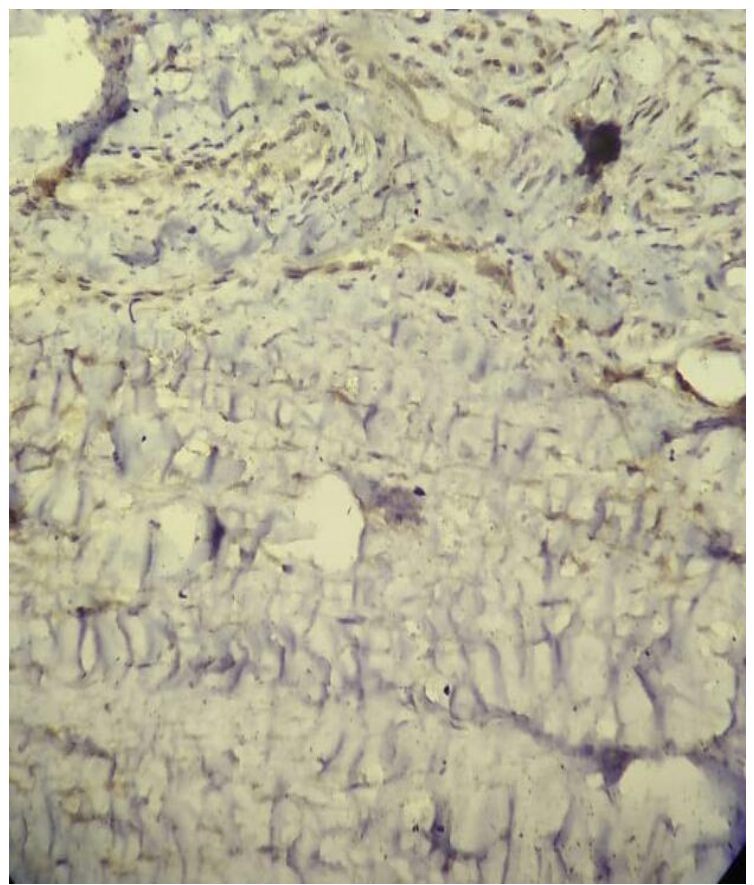

Fig-2: Tumor cells showing immunoreactivity for vimentin (400X)

\section{DISCUSSION}

Fibroma is a rare and benign soft tissue tumour that usually arises in the tendons or tendon sheath [9]. It typically develops in young adult males with peak of incidence in the $3^{\text {rd }}$ to $4^{\text {th }}$ decade [1].

The differential diagnosis of fibroma of tendon sheath may include epidermal cyst, mucinous cyst, neuroma, leiomyoma, nodular fasciitis, synovial sarcoma and tenosynovial giant cell tumour [10].
The clinical features of tenosynovial giant cell tumour are particularly similar to those of fibroma of tendon sheath. However, fibroma of tendon sheath is distinguished from tenosynovial giant cell tumour by its histopathological features which include the fact that giant cell tumour of tendon sheath are less hyalinized and more cellular than fibroma of tendon sheath and have histiocytes and monocytes as well as multinucleated giant cells, foam cells and hemosiderin laden macrophages[10,11].

It is unclear whether fibromas are the result of reactive proliferation or true neoplasm. Regarding the treatment of fibromas of tendon sheath, the lack of cases made it difficult to build a consensus. The prognosis after marginal excision of these lesions is generally good due to their slow growth and benign histologic appearance. Chung et al. found a local recurrence rate of $24 \%$ after excision [1]. However, moretti et al. stated in their study that none of the knee cases they studied before have reported any recurrence of the tumour[9]. These statements are corresponds to our case, one year after the tumour was resected the patient showed a good vascularization, neither sign of recurrence or neurological deficit

\section{CONCLUSION}

Fibromas should be included in a differential diagnosis of a soft tissue tumour arising from knee joint. However, the tumour must be excised completely. Careful follow-up is needed to observe the risk of recurrence and malignancy. 


\section{REFERENCES}

1. Chung EB, FM. Enzimger, Fibroma of tendon sheath, Cancer. 1979; 44(5): 1945-1954.

2. Hitora, T., Yamamoto, T., Akisue, T., Marui, T., Nagira, K., Ohta, R., \& Kurosaka, M. (2002). Fibroma of tendon sheath originating from the knee joint capsule. Clinical imaging, 26(4), 280-283.

3. Pulitzer, D. R., Martin, P. C., \& Reed, R. J. (1989). Fibroma of tendon sheath. A clinicopathologic study of 32 cases. The American journal of surgical pathology, 13(6), 472-479.

4. Maeda, K., Setsu, N., Kato, Y., Kawai, A., \& Kobayashi, E. (2017). Fibroma of Tendon Sheath Presenting Limited Flexion of the Fingers. Case reports in orthopedics, 2017.

5. Greene, T. L., \& Strickland, J. W. (1984). Fibroma of tendon sheath. The Journal of hand surgery, 9(5), 758-760.

6. Wang, B., Zhang, J., Li, G., \& Zhang, Z. (2016). Fibroma of a tendon sheath causing Guyon's canal syndrome: case report. Journal of plastic surgery and hand surgery, 50(4), 246-248.

7. Al-Qattan, M. M. (2014). Fibroma of tendon sheath of the hand: a series of 20 patients with 23 tumours. Journal of Hand Surgery (European Volume), 39(3), 300-305.

8. Capkin, S., \& Kaleli, T. (2019). Superficial radial nerve compression due to fibroma of the brachioradialis tendon sheath: A case report. Acta orthopaedica et traumatologica turcica.

9. Moretti, V. M., de la Cruz, M., Lackman, R. D., \& Fox, E. J. (2010). Fibroma of tendon sheath in the knee: a report of three cases and literature review. The Knee, 17(4), 306-309.

10. Heckert, R., Bear, J., summers, T., Frew, M., Gwinn, D., \& McKay, P. (2012). Fibroma of the tendon sheath-a rare hand tumor. Polish Journal of Surgery, 84(12), 651-656.

11. Fox, M. G., Kransdorf, M. J., Bancroft, L. W., Peterson, J. J., \& Flemming, D. J. (2003). MR imaging of fibroma of the tendon sheath. American Journal of Roentgenology, 180(5), 1449-1453. 